\title{
De Michel Pêcheux a outras epistemologias em Análise do Discurso
}

From Michel Pêcheux to other epistemologies in Discourse Analysis

Cleudemar Alves Fernandes ${ }^{1}$

Universidade Federal de Uberlândia - UFU

Israel de $\mathrm{Sá}^{2}$

Universidade Federal de Uberlândia - UFU

Vinícius Durval Dorne ${ }^{3}$

Universidade Federal de Uberlândia - UFU

\footnotetext{
${ }^{1}$ Professor Titular do Instituto de Letras e Linguística e do Programa de Pós-Graduação em Estudos Linguísticos. Líder do Laboratório de Estudos Discursivos Foucaultianos - LEDIF.

${ }^{2}$ Professor Adjunto do Instituto de Letras e Linguística. Vice-líder do Grupo Interinstitucional de Estudos em Discursos e Resistências - GEDIR.

${ }^{3}$ Professor Adjunto da Faculdade de Educação (curso de Jornalismo) e do Programa de Pós-Graduação em Estudos Linguísticos. Vice-líder do Laboratório de Estudos Discursivos Foucaultianos - LEDIF.
} 


\section{Introdução}

A Heterotópica nasce de uma inquietação quanto ao(s) espaço(s) e alcances da Análise do Discurso na contemporaneidade, e se propõe como um veículo outro para as reflexões desse campo de conhecimento. Logo, buscamos em outros olhares, nas formas diversas de manejar objetos, conceitos, práticas, as possibilidades de se fazer análise discursiva hoje. Esse desejo por uma teoria não subjetivista, pelo disperso, pelo não contínuo, pelo múltiplo, pelas possibilidades (sempre outras) de se olhar para o discurso se dá em decorrência do nosso tempo, da nossa época, marcada pela simultaneidade, pela justaposição, “[...] do próximo e do distante, do lado a lado, do disperso" (FOUCAULT, 2013, s/p).

Diante da impossibilidade de encontrar nas diversas maneiras de se pensar, fazer e dizer uma forma unívoca desenvolvida no curso do tempo, a Heterotópica propõe-se como "uma rede que liga pontos e entrecruza seu emaranhado" (FOUCAULT, 2013, s/p). Todavia, não se intenta buscar o espaço do dentro (interioridade, imanência, subjetivismos....), direciona-se para o espaço do fora (exterioridade, história, discurso, sentidos...). Espaço heterogêneo que constitui e é constituído por discursos e sujeitos, fruto de relações de sentido, de/entre sujeitos; logo, espaço nunca vazio, movente, que se abre a novas (e diversas) possibilidades de realização. Gestada com alicerce no conceito de Heterotopia, a Heterotópica firma-se como um lugar real, efetivo, inserido na própria instituição da sociedade, e convida para, no seu interior, no efeito de retorno, pela/na linguagem, fazer o pensamento existir e se reconhecer, e a verdade - fruto do discurso e da história - ser representada, contestada e invertida. Sendo assim, um lugar outro para o pensar (de outro modo).

A Heterotópica se desdobra, desta forma, como um suporte, ou um veículo, para o estudo, a análise, a descrição, a leitura dos mais variados objetos discursivos, sob diferentes perspectivas teóricas e/ou epistemológicas, tendo em vista as inter-relações entre linguagem, sujeito, história e sentidos. Tal como na metáfora do barco - lugar heterotópico por excelência -, sem o pensar "[...] os sonhos definham, a espionagem substitui a aventura, e a polícia, os corsários" (FOUCAULT, 2013, s/p).

Inserida nesse escopo, esta primeira edição temática da Heterotópica aborda as "Epistemologias das Análises do Discurso". Entendemos, com essa proposição, que perscrutar pelos diversos caminhos da Análise do Discurso exige, sobremaneira, compreender suas diferentes filiações (consequentemente, seus desdobramentos, conceitos e teorizações) frente a um sistema de referência em dada época, capaz de sustentar seus discursos teóricos; ou seja, trata-se de refletir à luz da epistemologia, tomada como "um húmus, e sobre ele só podem 
brotar certas formas de organização do discurso, sem que a confrontação com outras formas possa relevar de um julgamento de apreciação" (CANGUILHEM, 2012, p. 22-23).

Os textos reunidos nesta publicação buscam problematizar o alcance de diversas linhas da Análise do Discurso, suas aplicações, seus procedimentos analíticos, as maneiras próprias de operacionalizar a unidade / o objeto discurso. Sendo assim, valemo-nos das reflexões de Bachelard (2006) a respeito da física, para o campo do discurso, a fim de sinalizar que esse empreendimento não almeja, então, descobrir um único ponto de vista, ou antes, um ponto de vista fixo capaz de aglutinar as diferentes filiações; buscamos, ao contrário, ver se desdobrar o pluralismo (necessário) das correntes capazes de sinalizar a complexidade que os estudos do discurso demandam.

Se a episteme "[...] não é uma forma de conhecimento, ou um tipo de racionalidade que, atravessando as ciências mais diversas, manifestaria a unidade soberana de um sujeito, de um espírito ou de uma época" (FOUCAULT, 2008, p. 214), mas dados feixes de relações que permitiram um conhecimento, em um dado momento, no âmbito de suas regularidades discursivas, apresentar as problematizações em torno da AD é também reclamar "[...] o direito de desviar por um instante a ciência do seu trabalho positivo, da sua vontade de objectividade para descobrir o que resta de subjectivo nos métodos mais severos" (BACHELARD, 2006, p. 28). Destarte, é trazer à luz o campo epistemológico, em que a episteme manifesta-se assim uma/na história, que emerge frente às suas condições de possibilidade de existência.

Logo, trata-se de refletir que anseios, objetos, olhares, recortes, delimitações, problemas, tarefas reclamem formas próprias de pensamento e de trabalho com o discurso, e que suas descrições, então, desaguem em um campo inesgotável, que nunca pode ser fechado. Buscamos, dessa maneira, as falhas, as escansões, as defasagens, as (não) coincidências que não cessam de se estabelecer e de se desfazer.

Esta proposta esbarra também nas limitações de cada forma de olhar; não a limitação compreendida como devaneio, como imaginação, como o não-pensado/pensável, mas como possibilidade efetiva para as várias teorizações da Análise do Discurso, inserida em práticas histórica, linguística, psicanalítica etc..

Frente a isso, sabemos que as primeiras proposições da Análise do Discurso francesa, visando a sua edificação como campo disciplinar, tiveram dois alicerces bastante próximos, mas pautados em algumas diferenças. De um lado, Jean Dubois, um linguista renomado, para quem a "AD é a sequência 'natural' da lexicologia", cujo dispositivo para análise leva a um caráter "operacional concebido sobre um princípio estrutural” (MALDIDIER, 1994, p. 20). De outro, Michel Pêcheux, filósofo que refletia sobre a epistemologia das ciências, 
“demonstrava uma vontade de formalização que podia parecer provocadora na época: 'a máquina discursiva"” (MALDIDIER, 1994, p. 20). Ambos os pesquisadores estavam fortemente vinculados ao marxismo e envolvidos com questões políticas.

Desses primórdios, década de 1960, à atualidade (2019), a Análise do Discurso tornou-se um campo múltiplo, em termos de direções teóricas. Todavia, todas as tendências firmam-se em uma "derrocada" do sujeito do cogito cartesiano, que marcou uma mudança de epistemologia característica da era moderna, aquela que sustenta a morte do homem, compreendido como indivíduo fundado em si, a partir de uma interioridade própria, e promove o nascimento do sujeito descentrado, constituído pela exterioridade sócio-histórica, cuja existência é atestada pela linguagem. Temos aí um espaço amplo, complexo e aberto, propício a investigações inesgotáveis.

Não obstante, a Análise do Discurso se firma como uma área de pensamento transdisciplinar, uma vez que se apoia em disciplinas próximas, nas ciências humanas, tais como a Psicanálise, a Filosofia, a História etc. (PAVEAU; SARFATI, 2006). Tal condição exige do pesquisador rigor científico, teórico e metodológico, principalmente ao refletir que “[...] a indefinição, a mobilidade e a variedade do objeto 'discurso' reclamam, para que seu estudo seja satisfatoriamente e cientificamente rentável, uma sólida armadura conceitual" (PAVEAU; SARFATI, 2006, p.203). Como assevera Maldidier (2003), todos os teóricos buscavam a autonomia da Análise do Discurso, para além de qualquer aplicação da linguística a outro domínio, ou de uma mera integração ao campo da linguística.

É nesse sentido que, em se tratando das Análises do Discurso, na atualidade, cada linha alicerça-se em epistemologias internas e regionais, "porque são elaboradas a partir de dentro pelos cientistas interessados, e [...] cada uma se constrói segundo necessidades [próprias]" (BLANCHÉ, 1988, p. 23).

Diante disso, com a proposição deste um número temático da Heterotópica objetivamos justamente reunir trabalhos que remontem às epistemologias próprias a cada vertente da Análise do Discurso vigente na atualidade. Essa proposta leva em conta, portanto, a emergência de novas e diferentes abordagens dos estudos discursivos, que se consolidaram e se transformaram desde os primeiros trabalhos de Dubois e Pêcheux, e a necessidade atual de problematizar seus campos de investigação, o modo como delimitam seus objetos e a constituição de seus arsenais teórico-metodológicos. Seguramente, as reflexões publicadas neste número temático são de grande importância para os estudos discursivos em geral, uma vez que mostram a atualidade desse campo de saber e as especificidades próprias das vertentes que o constituem. 
Feitas estas considerações, procederemos a seguir a uma exposição do trabalho de Michel Pêcheux na fundação da Análise do Discurso. Não traçaremos um histórico, no sentido de detalhar os deslocamentos propostos pelo próprio Pêcheux; apontaremos cortes epistemológicos por ele efetuados para a proposição do discurso como um novo objeto para análise e, ao mesmo tempo, como um conceito. Pretendemos assinalar aspectos desse percurso que resultou na edificação da Análise do Discurso.

\section{Michel Pêcheux e a edificação da Análise do Discurso}

As proposições de Michel Pêcheux sobre discurso cumprem dupla finalidade acerca da Análise do Discurso como um campo disciplinar edificado. Primeiramente, há em seu pensamento um gesto inaugural de objetos e conceitos que arquitetarão essa disciplina; em seguida, ou mesmo concomitante a isso, suas elaborações teóricas consolidam a Análise do Discurso como uma disciplina que se assenta no rol dos estudos linguísticos. De uma maneira sucinta, ancorados em Maldidier (2003), afirmamos que Pêcheux define o discurso como um objeto a ser investigado e, ao mesmo tempo, como um conceito. Tal feitura se dá pela asseveração da ideologia e da língua como o que se entrecruzam na materialização do discurso, dando-lhe existência e possibilitando-lhe atuar na produção do sujeito e do sentido. Esse empreendimento efetua-se na instalação do objeto discurso pela recorrência a três áreas teóricas: linguística, história e psicanálise.

Nesse gesto inaugural, uma das primeiras assertivas de Pêcheux, e que sofrerá algumas reelaborações e aprofundamentos em seu percurso teórico, é a de que "os sujeitos acreditam que 'utilizam' seus discursos quando na verdade são seus 'servos' assujeitados, seus "suportes"” (PÊCHEUX, 1990a, p. 311). Esta afirmação vincula-se a suas considerações sobre a ideologia perpassada pela linguagem.

A concepção do objeto discurso, acompanhada de um conjunto de conceitos diretamente associados à metodologia de trabalho, decorre de cortes e deslocamentos de diferentes campos disciplinares. Da linguística, "compreendida como teoria dos mecanismos sintáticos e dos processos de enunciação ao mesmo tempo" (PÊCHEUX; FUCHS, 1990, p. 163), nega-se a imanência do significado em proveito da noção de sentido, que reitera o descentramento do sujeito - o sujeito não é origem do próprio dizer e não tem controle dos sentidos, ao que Pêcheux (1997a) denominará de esquecimentos. Certos questionamentos e 
contestações à linguística imanente, à linguística do enunciado, também serão arrolados, em virtude das possibilidades de focalizar os aspectos semânticos como integrantes dos processos históricos resultantes das formações e transformações sociais. Da história, filiado ao marxismo althusseriano, busca-se o materialismo histórico, abarcado "como teoria das formações sociais e de suas transformações, compreendida aí a teoria das ideologias" (PÊCHEUX; FUCHS, 1990, p. 163). Sentido e sujeito são produzidos na história, em batimento com a ideologia, e é referenciado no materialismo histórico que o discurso é indicado em relação com a ideologia. Da psicanálise, considerada como uma das possibilidades de estudar a não transparência do sujeito, focaliza-se o inconsciente que se estrutura pela linguagem, cujo funcionamento mostra que as questões de linguagem dizem respeito à constituição do sujeito. Por esse viés, apreendem-se as ponderações sobre o sujeito em sua relação com o simbólico, e vislumbra-se também uma ligação do inconsciente com a ideologia. Como mostra Pêcheux (1997a, p. 300), o deslizamento de sentidos, via funcionamento do inconsciente, deixa traços no sujeito-ego da forma-sujeito ideologia.

Por essas recorrências, especificamente sobre o discurso como objeto e conceito, Pêcheux e Fuchs (1990, p. 164) asseveram "a teoria do discurso como teoria da determinação histórica dos processos semânticos". Visualizamos, portanto, a organização e proposição de uma disciplina que implica batimento entre teoria, objeto e método de análise. Destacamos também a exterioridade (histórica, social, ideológica) considerada como condição de produção do discurso: "a referência às condições de produção designava a concepção central do discurso determinado por um 'exterior' [...] para evocar tudo o que, fora a linguagem, faz com que o discurso seja o que é: o tecido histórico-social que o constitui” (MALDIDIER, 2003, p. 23).

Em suas reflexões sobre o trabalho de Michel Pêcheux, Maldidier (2003) afirma que o seu empreendimento proporcionou a construção de um objeto radicalmente novo: o discurso. A autora considera seu projeto como uma grande construção iniciada com a proposição de uma Análise Automática do Discurso (AAD) - tese de doutoramento defendida por Michel Pêcheux em 1968. Neste estudo, Pêcheux procurou desenvolver um dispositivo técnico complexo informatizado, por meio do qual vislumbrou um conjunto de procedimentos computadorizados que pudessem funcionar como uma máquina de ler, que arrancaria a leitura da subjetividade. Considerando ainda (e fundamentalmente nesse momento) a ligação da ciência com a política, para Pêcheux, a teoria do discurso teria uma relação direta e forte com uma teoria da ideologia e com uma teoria do inconsciente. Reside nesse eixo central a tríplice aliança entre Marx (relido por Louis Althusser, com atenção especial para o materialismo 
histórico), Freud (relido por Lacan, com foco no inconsciente) e Saussure (relido pelo próprio Pêcheux, que problematiza a língua como sistema autônomo e assenta-se na linguística). Essa tríplice aliança, amplamente discutida nos textos de Michel Pêcheux, fornece subsídios para a sustentação de suas teses, para suas refutações e para a construção de suas reflexões teóricas.

Se em Pêcheux, o linguístico, o histórico e o ideológico coexistem em uma relação de implicância, compreendidos como discurso (exterioridade à langue e à parole), há um atravessamento do materialismo histórico na linguística, e é no interior de problemas colocados pela linguagem que essa exterioridade tem eco. Com a assunção desse entrelaçamento teórico/epistemológico, Maldidier (2003) afirma que com a AAD 69 Pêcheux se fez linguista. Assim o sendo, suas teorizações e/ou reflexões sobre a linguística inscrevemna nas rupturas de paradigmas próprias às ciências humanas, características da era denominada Modernidade. Esses cortes apresentam contextos epistemológicos regionais, em campos disciplinares específicos, voltados para reflexões acerca dos próprios métodos e aparatos teóricos, e, por vezes, caracterizados pelo entrecruzamento de diferentes disciplinas. Nas problematizações pecheutianas, observamos asseverações sobre o descentramento de uma linearidade própria à organização interna de um campo científico, bem como questionamentos acerca da homogeneidade teórica e metodológica dos saberes conclamados como próprios a cada disciplina. Especificamente sobre a linguística, lemos:

Se a Linguística é solicitada a respeito destes ou daqueles pontos exteriores a seu domínio, é porque, no próprio interior de seu domínio (em sua prática específica), ela encontra, de um certo modo, essas questões sob a forma de questões que lhe dizem respeito ("você não me procuraria se já não tivesse me encontrado"). A Linguística não seria afetada por exigências em direção à "Semântica" se ela já não tivesse se encontrado, de algum modo, com essas questões... no seu interior (PÊCHEUX, 1997a, p. 88).

Para a sustentação de seu constructo teórico, Pêcheux (1998, p. 24) afiança que a linguística até então assenta suas investigações em universos discursivos logicamente estabilizados, que "garantem maciçamente o atual embasamento da linguística em conceitos lógicos, semânticos e pragmáticos importados dessa série de universos". A essa tendência então predominante na forma de tratamento do corpus em linguística, ele imputa severas refutações. Com respaldo em Benveniste, alardeia que "a linguagem é realmente o que há de mais paradoxal no mundo, e infelizes são os que não veem" (BENVENISTE apud PÊCHEUX, 1998, p. 21). Opondo-se a esse alinhamento da linguística, Pêcheux (1998, p. 24) assevera: “qualquer língua natural é também, antes de mais nada, a condição de existência de 
universos discursivos não-estabilizados logicamente, próprio ao espaço sócio-histórico dos rituais ideológicos, dos discursos filosóficos, dos enunciados políticos, da expressão cultural e estética" (Grifos do autor). Diante dessas contestações, o autor firma-se nesta asserção assegurando a relação língua e ideologia como o que possibilita a materialidade discursiva. Firmando-se nesse viés teórico, acrescenta:

[...] o objeto da Linguística aparece [...] assim atravessado por uma divisão discursiva entre dois espaços: o da manipulação de significações estabilizadas, normatizadas por uma higiene pedagógica do pensamento, e o das transformações do sentido, escapando a toda norma a priori, de um trabalho do sentido sobre o sentido, tomado no lance indefinido das interpretações (PÊCHEUX, 1998, p. 25).

Considerando que "Saussure constitui, direta ou indiretamente, a pedra de toque de todas as escolas linguísticas atuais" (PÊCHEUX; GADET, 2004, p. 55), Pêcheux procura no Cours de Linguistique Générale alguns cortes conceituais para a teoria do discurso. Para tal, discute a conceituação saussuriana de língua apontando-lhe duas definições. A primeira destacada refere-se à língua como parte social da linguagem, exterior ao indivíduo. A segunda é a afirmação de que a língua é uma instituição social, de natureza semiológica, distinta das outras instituições, e mais importante que todas as outras. Com essa imergência, considera que o discurso, do ponto de vista saussuriano, é da ordem da fala, "na qual se manifesta a "liberdade do locutor"'. Contudo, do ponto de vista da sociologia, tomando como referência Pierre Bourdieu, o discurso "é uma parte de um mecanismo em funcionamento, isto é, como pertencente a um sistema de normas nem puramente individuais nem globalmente universais, mas que derivam de uma ideologia política, correspondendo, pois, a um certo lugar no interior de uma formação social dada" (PÊCHEUX, 1990b, p. 76). Com esse percurso teórico-reflexivo, chega-se à noção de condições de produção, que possibilitam que um discurso seja pronunciado.

Feitas essas reflexões e ponderações, Michel Pêcheux apresenta a seguinte proposição, de caráter geral:

Os fenômenos linguísticos de dimensão superior à frase podem efetivamente ser concebidos como um funcionamento, mas com a condição de acrescentar imediatamente que este funcionamento não é integralmente linguístico, no sentido atual desse termo e que não podemos defini-lo senão em referência ao mecanismo de colocação dos protagonistas e do objeto de discurso, mecanismo que chamamos de 'condições de produção' do discurso (PÊCHEUX, 1990b, p. 78, grifos do autor). 
De forma específica, temos a asseveração pecheutiana de que é impossível analisar um discurso como um texto, ou como uma sequência linguística encerrada em si. Para analisar discurso é necessário considerar o estado das condições de produção. Isto é, deve-se considerar que o discurso tem existência na exterioridade do linguístico, no social, é marcado sócio, histórico e ideologicamente. Discurso não se confunde com discurso empírico, nem com texto, nem com qualquer concepção comunicacional da linguagem. A propósito, há nessas elaborações teóricas uma contestação ao esquema da comunicação, ou esquema da informação, de Roman Jakobson, o que corrobora o descentramento do sujeito e ostenta a produção do sentido face à inscrição ideológica da enunciação, dos lugares históricos e sociais nos quais os sujeitos em enunciação se inscrevem. De acordo com as posições dos sujeitos envolvidos, a enunciação tem um sentido e não outro(s).

Nessa acepção, o sentido é considerado um efeito de sentido da enunciação entre $A$ e $B$, é o efeito da enunciação do enunciado. Isto, considerando que $A$ e $B$ representam diferentes sujeitos em interlocução, inscritos em espaços socioideológicos específicos.

O sentido de uma sequência só é materialmente concebido na medida em que se concebe esta sequência como pertencente necessariamente a esta ou àquela formação discursiva [...] Trata-se de um "efeito de sentidos" entre os pontos A e B. [...] Os elementos A e B designam algo diferente da presença física de organismos humanos individuais. [...] A e B designam lugares determinados na estrutura de uma formação social (PÊCHEUX; FUCHS, 1990, p. 169).

Das edificações pecheutianas por meio de reflexões e contestações a conceitos da linguística, a noção de sentido é esboçada também pela discussão ou debate com a linguística saussuriana. Para tal proposição, Pêcheux, Haroche e Henry (2011) retomam o princípio da subordinação da significação ao valor, considerando que, em Saussure, a significação é da ordem da fala e do sujeito, enquanto o valor liga-se à língua como sistema, e questionam a especificidade da semântica e o alcance da linguística no que concerne ao sentido. Os autores reconhecem e reiteram a produtividade do corte saussuriano para a linguística geral, mas esboçam alguns questionamentos sobre a demonstração de Saussure de que do ponto de vista da língua apenas o valor é considerado e não a significação. O argumento impetrado é de que em estudos particulares de línguas, ou de estados de uma língua, a teoria semântica geral não alcança as especificidades em questão. O mesmo é afirmado quando se trata de discursos específicos: "as palavras podem mudar de sentido segundo as posições determinadas por 
aqueles que as empregam" (PÊCHEUX; HAROCHE; HENRY, 2011, p. 19, grifos dos autores). Esta tese é apresentada também em Pêcheux (1997a, p. 160):

[...] o sentido de uma palavra, de uma expressão, de uma proposição, etc., não existe "em si mesmo" [...] ao contrário, é determinado pelas posições ideológicas que estão em jogo no processo sócio-histórico no qual as palavras, expressões e proposições são produzidas (isto é, reproduzidas). Poderíamos resumir esta tese dizendo: as palavras, expressões, proposições etc., mudam de sentido segundo as posições sustentadas por aqueles que as empregam (Grifos do autor).

Conforme expõe Maldidier (2003), e reiteramos, essas reflexões levam à constatação de que o sentido, objeto da semântica, excede o âmbito da linguística. Isto, porque "o laço que une as 'significações' de um texto às suas condições sócio-históricas não é meramente secundário, mas constitutivo das próprias significações" (PÊCHEUX; HAROCHE; HENRY, 2011, p. 19, grifos dos autores). A autora supracitada relembra ainda a presença de um algoritmo contundente no pensamento de Michel Pêcheux: "há um funcionamento das línguas em relação a elas mesmas, isto precisamente que a linguística descreve quando fala de fonologia, de morfologia, e talvez de sintaxe" (MALDIDIER, 2003, p. 31, grifos da autora). Considerando esse funcionamento autônomo, M. Pêcheux arquiteta os fundamentos do discurso do lado da linguística, como objeto e conceito, mas para tal, firma-se fortemente, e inclusive movido por convicção política, no materialismo histórico para fazer a indicação/exposição desse objeto diretamente vinculado à ideologia.

Fundamentado no materialismo histórico, considerando os mecanismos sintáticos e os processos de enunciação com respaldo na linguística, Michel Pêcheux esboça o discurso em relação com a ideologia. Nessas elaborações, a noção de formação discursiva, conceito que sofre revisões e modificações em seu pensamento, é proposta como integrante de formações ideológicas pensadas, por sua vez, como forças em confronto diretamente relacionadas $a$ posições de classes sociais em conflito umas com as outras. O conceito de formação discursiva implica considerar no interior do discurso a "exterioridade relativa" da formação ideológica.

As formações ideológicas [...] comportam necessariamente, como um de seus componentes, uma ou várias formações discursivas interligadas que determinam o que pode e deve ser dito (articulado sob a forma de uma arenga, um sermão, um panfleto, uma exposição, um programa etc.) a partir de uma posição dada numa conjuntura (PÊCHEUX; FUCHS, 1990, p. 169). 
As bases do materialismo histórico são buscadas centralmente em Louis Althusser, em especial na publicação de Ideologia e Aparelhos Ideológicos de Estado, em 1970. Nesta publicação, considerando a interpelação, Althusser esboça a categoria sujeito da ideologia e, além de fornecer os impulsos iniciais a Pêcheux, se faz presente teórica e politicamente em todo o seu percurso. Aliás, “Althusser é, para Michel Pêcheux, aquele que faz brotar a fagulha teórica, o que faz nascer os projetos de longo curso" (MALDIDIER, 2003, p. 18). Tendo se tornado marxista de formação acadêmica, em seus escritos, Pêcheux promove uma ligação da teoria com a política, aspecto confirmado, inclusive, pelo firmamento no materialismo histórico. "É a partir do materialismo histórico que se faz a indicação de novos objetos, no caso o discurso, explicitamente posto em relação com a ideologia" (MALDIDIER, 2003, p. $32)$.

Nesse contexto epistemológico, Pêcheux delineia em sua obra de maior densidade teórica, Les vérités de la Palice, de 1975 (na tradução brasileira, Semântica e Discurso: uma crítica à afirmação do óbvio), uma teoria não subjetivista da subjetividade, tendo como objetivo central a edificação, ou melhor, a proposição de uma teoria materialista do discurso. "O discurso é a figura central do livro. Ele liga todos os fios: da linguística e da história, do sujeito e da ideologia, da ciência e da política" (MALDIDIER, 2003, p. 45). Em Semântica e Discurso, Pêcheux aponta uma ligação da ciência com a ideologia e reflete sobre o sujeito nessa relação. Considerando que a ideologia tem uma forma, e firmando-se na proposição althusseriana de que a ideologia interpela os indivíduos em sujeitos, Pêcheux (1997a) contesta, então, a ideia de neutralidade da ciência.

Nesse momento teórico, a filosofia também é evocada nas reflexões desenvolvidas. Nesta feita, nas discussões e aprofundamentos sobre a ideologia em relação com a ciência, com o discurso, com o sentido e com o sujeito, o idealismo é refutado em defesa do materialismo. Para o idealismo, as ideologias são consideradas como ideias originárias nos sujeitos, o que Pêcheux, ao asseverar que as ideologias têm forças materiais e são constitutivas dos sujeitos, toma como um erro. Para ele, a ideologia interpela o indivíduo em sujeito, promove-lhe o assujeitamento e, ao mesmo tempo, oferece-lhe a ilusão, que funciona como certeza, de liberdade. Assim, Pêcheux defende uma teoria materialista dos processos discursivos para defender também o assujeitamento do sujeito pela ideologia, e ainda reitera que o sujeito ideológico não é sempre-já dado.

Nesse eixo teórico, vislumbrando esclarecer a teoria materialista do discurso, as discussões seguem, iluminadas por Althusser, por meio da explicitação das determinações ideológicas e econômicas da produção, reprodução e transformação das relações de produção, 
pensadas, em seu turno, como intrínsecas às formações sociais. Reside aí o caráter contraditório dos modos de produção cuja característica é a luta de classes. Nesse momento, a ideologia é caracterizada como forma, força, exercício de dominação utilizado pelos Aparelhos Ideológicos de Estado, que constituem um conjunto complexo que a formação social comporta. Esse conjunto é marcado por "relações de contradição-desigualdadesubordinação" (PÊCHEUX, 1997a, p. 145). Essa contradição pode ser lida no interior do próprio discurso, pela maneira como ele organiza a dominação da ideologia dominante.

Para a sustentação da teoria materialista dos processos discursivos, a tese central de Althusser - a ideologia interpela os indivíduos em sujeitos - é reapresentada, seguida das seguintes explicações:

“1) Só há prática através de e sob uma ideologia;

2) Só há ideologia pelo sujeito e para sujeitos" (PÊCHEUX, 1997a, p. 149).

O funcionamento da ideologia e do inconsciente produzem em si a dissimulação de sua própria existência. Esse jogo dos efeitos ideológicos, afirma o autor, está em todos os discursos. Assim, a constituição do sentido vincula-se à constituição do sujeito na corporatura da interpelação.

A interpelação do indivíduo em sujeito de seu discurso se efetua pela identificação (do sujeito) com a formação discursiva que o domina (isto é, na qual ele é constituído como sujeito): essa identificação, fundadora da unidade (imaginária) do sujeito, apoia-se no fato de que os elementos do interdiscurso (sob sua dupla forma, [...] enquanto "pre-construído" e "processo de sustentação') que constituem, no discurso do sujeito, os traços daquilo que o determina, são re-inscritos no discurso do próprio sujeito (PÊCHEUX, 1997a, p. 163).

O sujeito não é origem de si, mas o funcionamento da contradição promove o apagamento do fato de que ele (o sujeito) resulta de um processo, colocando-o como causa de si.

Nessa análise do discurso materialista, há uma relação dos sentidos com as formações discursivas, que, inscritas em formações ideológicas, determinam o que deve e pode ser dito; ou seja, os sentidos são produzidos pela inscrição das palavras, das proposições etc. nas formações discursivas em que são produzidas, nas quais e pelas quais os indivíduos são interpelados em sujeitos.

Uma formação discursiva, por sua vez, constitui-se de outras formações discursivas, de elementos que vêm de seu exterior, ao que Pêcheux denominou de pré-construído (discursos que a antecedem, o já-lá). Nesse momento de formulação teórica, é esboçado o 
conceito de interdiscurso, para designar o exterior de uma formação discursiva (isso fala, sempre antes, em outro lugar). Interdiscurso é "esse 'todo complexo com dominante' das formações discursivas [...] submetido à lei da desigualdade-contradição-subordinação" (PÊCHEUX, 1997a, p. 162). E, mais adiante, “o interdiscurso determina a formação discursiva com a qual o sujeito, em seu discurso, se identifica, sendo que o sujeito sofre cegamente essa determinação, isto é, ele realiza seus efeitos 'em plena liberdade"” (PÊCHEUX, 1997a, p. 215). Dessa maneira, a formação discursiva dominante veicula a forma-sujeito do discurso. Essa forma-sujeito resulta da identificação do sujeito com a formação discursiva que o constitui assegurando-lhe sua unidade imaginária. Todavia, como mostra o autor, nesse processo pode ocorrer também a contraidentificação do sujeito com a formação discursiva dominante, por meio de um trabalho de transformação e/ou deslocamento da forma-sujeito. Nesse funcionamento, ideologia e inconsciente dissimulam sua própria existência fazendo com que o sujeito se veja como origem ou causa de si. Em síntese, a interpelação identificação produz o assujeitamento dissimulando-o.

Nesse laborioso empreendimento teórico, Pêcheux (1997a) considera a produção dos conhecimentos científicos e sua incidência sobre os processos discursivos inscrita nas condições de (re)produção e transformação das relações de produção, ligadas à ideologia, em suas formas práticas. Não existe sociedade e história independentes das relações de produção e lutas de classe. Usando palavras do próprio Pêcheux, consideramos a Análise do Discurso um evento epistemológico, um corte epistemológico por meio do qual foram "produzidos conceitos fundadores de uma ciência, e que marca, assim, seu começo histórico" (PÊCHEUX, 1997a, p. 192, grifos do autor). Considerando esse corte para a fundação da Análise do Discurso, Pêcheux (1997a, p. 192) acrescenta:

[...] o próprio dos conhecimentos [...] que precedem o corte em um campo epistemológico dado é que eles permanecem inscritos na forma-sujeito, isto é, que eles existem sob a forma de um sentido evidente para os sujeitos - seus suportes históricos - através das transformações históricas que afetam esse sentido. O que resulta disso no que se refere à discursividade é [...] que o efeito de conhecimento coincide, nessas condições, com um efeito de sentido inscrito no funcionamento de uma formação discursiva (Grifos do autor).

Se o corte epistemológico implica a inauguração científica, ou inauguração de um campo disciplinar, o sucesso do trabalho de Michel Pêcheux, juntamente com seu grupo, é inquestionável. Como assinalamos, o trabalho de edificação da Análise do Discurso se deu por meio de uma luta na formulação e reformulação de conceitos e daquilo que eles designam. 
Nesses gestos de revisões e reformulações, Pêcheux (1997b), em releituras de conceitos da psicanálise, constata que o non-sens inconsciente nunca é recoberto pela evidência do sujeito-centro-sentido, ele aparece sempre: "os traços inconscientes do significante não são jamais 'apagados' ou 'esquecidos' mas trabalham, sem se deslocar, na pulsação sentido/non-sens do sujeito dividido" (PÊCHEUX, 1997b, p. 300). E, ainda, “a ordem do inconsciente não coincide com a da ideologia [...] mas isso não significa que a ideologia deva ser pensada sem referência ao registro inconsciente" (PÊCHEUX, 1997b, p. 301). A noção de falha, colocada pela psicanálise como "só há causa daquilo que falha" incomoda Pêcheux mediante a averiguação de que, como há uma ligação do inconsciente com a ideologia, os deslizamentos de sentidos pelo funcionamento do inconsciente se relacionam à forma-sujeito da ideologia, que não pode ser pensada sem referência ao inconsciente. Logo, algo falha do lado do inconsciente e também do lado da ideologia. Além de retificações, há aberturas na Análise do Discurso que conclamam a investigações.

Como assinalamos, dos primeiros gestos de fundação da Análise do Discurso, e em todo o percurso empreendido por Michel Pêcheux, essa disciplina se mostrou inquieta com seu objeto e com seus conceitos. A natureza do objeto (movente, produzido, reproduzido, deslocado, transformado, descontínuo) sempre recolocou, e recoloca, questões; o que torna a investigação inesgotável, e o campo disciplinar aberto a deslocamentos, a transformações, a uma edificação ininterrupta. Na ebulição do calor teórico e metodológico da Análise do Discurso, na inquietação que essa disciplina causava aos pesquisadores com ela envolvidos, em abril de 1980, em Nanterre, foi realizado o Colóquio "Materialidades Discursivas". Nesse momento, a Análise do Discurso já procurava abarcar os discursos cotidianos, e depara-se com inúmeras indagações sobre o próprio objeto, sobre o papel dos analistas de discurso, sobre questões metodológicas e teóricas. Reuniram-se, nesse evento, linguistas, historiadores, psicanalistas, analistas do discurso, todos tocados pelas abrangências, limitações e, talvez principalmente, por questões que margeavam seus campos disciplinares, conclamando-os a deslocamentos. Nessa efervescência, uma das primeiras questões motivadoras para o debate foi a indagação, que é também um tema, "para onde vai a Análise do Discurso?" Os debates apontaram muitas possibilidades de investigação, mas visualizamos, já nesse momento, em retrospectiva, essa disciplina como uma abertura que se coloca para o estudo dos objetos que dizem respeito a ela.

Michel Pêcheux, em 1983, em um de seus últimos textos, considerando a especificidade da Análise do Discurso pela sua relação com a língua, aponta diferentes perspectivas desse campo disciplinar então vigentes na França. 
Ela compartilha, com a tradição lexicométrica a prática de construção de um corpus e o recurso eventual a algoritmos informatizados, mas ela não se impede de supor estruturas sintáticas sob a sequência de unidades lexicais.

Por outro lado, ela compartilha com as tradições semiológicas e semióticas (que, aliás, designam, às vezes, seus trabalhos como análises de discurso) a tarefa de apreender e descrever as condições estruturais de existência do sentido, mas sem se autorizar supor estruturas lógico-semânticas subjacentes às sequências discursivas.

Ela compartilha, finalmente, com a perspectiva arqueológica foucaultiana, a tarefa de levar em conta as condições históricas de existência de discursos em sua heterogeneidade, mas ela visa reintroduzir, explicitamente nesse campo, a problemática da língua (PÊCHEUX, 2011, p. 228).

Essas tendências têm ecos na atualidade, e, conforme mostraremos no tópico seguinte, muitas outras coexistem com elas.

Para encerrar este tópico, trazemos as palavras de Denise Maldidier, em quem nos apoiamos para a exposição do trabalho de Pêcheux.

O percurso de Michel Pêcheux deslocou alguma coisa. De uma ponta à outra, o que ele teorizou sob o nome de "discurso" é o apelo de algumas ideias tão simples quanto insuportáveis: o sujeito não é a fonte do sentido; o sentido se forma na história através do trabalho da memória, a incessante retomada do já-dito; o sentido não pode ser cercado, ele escapa sempre. Por causa de Michel Pêcheux, o discurso [...] não se confunde com sua evidência empírica; ele representa uma forma de resistência intelectual à tentação pragmática. Este pensamento continua a trabalhar em certas pesquisas sobre o discurso. Para além da linguística, ele permitiu a abertura de novas pistas na história, em sociologia, em psicologia, por todo lugar onde se tem a ver com textos, onde se produz o encontro da língua com o sujeito (MALDIDIER, 2003, p. 96).

A seguir, considerando a inquietação da Análise do Discurso com seu objeto e também com suas elaborações teóricas, apresentamos os textos reunidos nesta publicação. Cada um, a sua maneira, esboça uma linha de investigação dos estudos do discurso.

\section{Epistemologias da Análise do Discurso}

Nosso percurso epistemológico pela Análise do Discurso atesta, em um primeiro momento, a produtividade do pensamento de Michel Pêcheux como o que, para além da edificação da Análise do Discurso, ilumina, na atualidade, trabalhos de investigação realizado por vários pesquisadores. Diretamente vinculado a esse pensamento, ou por meio da busca de outras possibilidades de cortes epistemológicos, a Análise do Discurso, atualmente, comporta 
uma ramificação de tendências epistemológicas; e é justamente a isso que dedicamos esta publicação temática, cujos artigos passamos a apresentar.

Destacando questões da ordem da linguística, Henry Hernandez Bayter (Université de Lille), com o texto "Análisis del discurso: de la lexicometría a la fraseología. El caso de los sintagmas nominales en el discurso político colombiano", primeiro artigo desta publicação, vale-se de um programa lexicométrico para analisar os dois textos do acordo de paz na Colômbia. Com isso, torna-se possível analisar as diferentes formas nominais que são ali constituídas e fixadas e as estratégias discursivas utilizadas na produção de sentidos. Este método inscreve, então, um importante retorno às questões iniciais colocadas tanto por Pêcheux quanto por Dubois da articulação entre língua e discurso.

Diretamente ligado a um dos apontamentos das tendências da Análise do Discurso feitos por Pêcheux (2011), o segundo artigo, intitulado "Há em Foucault um gesto inaugural nos estudos discursivos?", de Vanice Maria Oliveira Sargentini (Universidade Federal de São Carlos), explicita o papel de Michel Foucault, especialmente com os trabalhos desenvolvidos em $A$ arqueologia do saber e $A$ ordem do discurso, na formação de um campo de estudos discursivos. Nesse sentido, a autora mostra como esse gesto inaugural está associado a um campo conceitual que abarca as noções de discurso, formação discursiva, enunciado, arquivo, descontinuidade, sistema. Seu objetivo é, portanto, validar a constituição de um campo de pesquisa que, a despeito dos cortes e das reconfigurações, reverbera incessantemente na atualidade.

Sob outra visada, o atravessamento da teoria psicanalítica na Análise do Discurso, assinalado como necessário nos textos fundadores dessa disciplina, constitui a proposta de discussão de Ane Ribeiro Patti (Centro Universitário Barão de Mauá) e Lucília Maria Abrahão e Sousa (Universidade de São Paulo) em "O(s) sujeito(s) do/no crime: efeitos de falta, resíduos incompletos". As autoras retomam teoricamente o modo como a noção de sujeito é trabalhada na Psicanálise e na Análise do Discurso e procedem à análise dos dizeres aos e dos sujeitos do/no crime em uma charge de Angeli, publicada na Folha de São Paulo. Mostram, assim, a proficuidade desta linha de investigação para os estudos discursivos.

Inscrito em uma epistemologia outra, não filiada ao pensamento de Michel Pêcheux, o artigo de Grenissa Bonvino Stafuzza (Universidade Federal de Goiás - Regional Catalão), intitulado "O Círculo de Bakhtin (Volóchinov e Medviédev) no Brasil: episteme, autoria e tradução em perspectiva dialógica", põe luz sobre a perspectiva dialógica do Círculo de Bakhtin, especialmente no modo como questões sobre episteme, autoria e tradução de seus 
escritos fundamentam uma produção científica brasileira e, ao mesmo tempo, influenciam diversas leituras da obra desse grupo na contemporaneidade.

O quinto artigo aqui ajuntado, de Roberto Leiser Baronas (Universidade Federal de São Carlos) e Samuel Ponsoni (Universidade Estadual de Minas Gerais), sob o título "Uma análise de discurso de base enunciativa: notas de leitura sobre o percurso epistemológico de Dominique Maingueneau", apresenta o percurso teórico-metodológico do analista do discurso francês Dominique Maingueneau acerca de uma análise de discurso de base enunciativa. $\mathrm{O}$ texto, perpassado por uma proposta de trabalho discursivo sobre os escritos do linguista brasileiro Mattoso Câmara Jr, divide-se em duas partes: na primeira, os autores expõem ideias-força desenvolvidas por Maingueneau ao longo de seu percurso acadêmico; na segunda, mostram como uma dessas ideias-força (a Filosofia como instituição discursiva) ilumina diversos trabalhos de pesquisadores brasileiros, na atualidade.

Rediscutindo questões teóricas da Análise do Discurso, inclusive com referência a Michel Pêcheux, com o artigo "Une sémantique du discours «au travail» de l'actualité: éléments pour l'analyse du discours des médias", Sophie Moirand (Université Sorbonne Nouvelle - Paris 3) reflete sobre a articulação entre discurso e mídia com o objetivo de mostrar como o tratamento da atualidade pelas mídias profissionais permite "repensar" tanto a Análise do Discurso de origem francesa quanto os estudos de discursos midiáticos. Para isso, a autora toma como exemplo analítico, ao longo de todo o texto, produções midiáticas que repercutem o atentado contra os espaços de culto muçulmano na Nova Zelândia, ocorrido em março de 2019.

Apresentando outra direção epistemológica para os trabalhos no campo da Análise do Discurso, Kátia Menezes de Sousa (Universidade Federal de Goiás / Universidade Federal de Uberlândia), com o texto "A genealogia e a ética foucaultianas nos estudos discursivos", retorna a Michel Foucault para discutir a problemática discursiva em seus últimos trabalhos, que põem luz sobre a genealogia e a ética. Seu objetivo é, portanto, mostrar como o filósofo francês chega ao entendimento da ética como resultado da relação do sujeito consigo mesmo, em que ele se constitui como sujeito moral de suas próprias ações. Com isso, a autora trata dos deslocamentos teóricos do percurso foucaultiano, da relação do discurso com a constituição de um sujeito ético e dos modos de ser do sujeito a partir das práticas de si.

Outra vertente epistemológica para as investigações em Análise do Discurso nos é apresenta por Mariano Dagatti (Universidad de Buenos Aires). Com foco nas retóricas políticas, que oferecem uma experiência multissensorial da política, e na relação entre análise do discurso e linguística, em "La vida por las ideas. La retórica romántica del Kirchnerismo 
(Argentina, 2003-2015)", o autor apresenta os resultados de uma investigação sobre os discursos públicos do chamado "kirchnerismo". Suas análises voltam-se para a construção de uma retórica romântica, um dos traços fundamentais de sua identidade, que envolve diferentes e variadas performances discursivas.

Mais uma visada epistemológica no rol das tendências em Análise do Discurso é exposta no artigo de Barbara De Cock (Université Catholique de Louvain), Daniel Michaud Maturana (Université Catholique de Louvain) e Marcela Alejandra Ruiz Zúñiga (Universidad Alberto Hurtado), "Un enfoque cognitivo del análisis del discurso: el caso de informes de Derechos Humanos en Chile", com o qual encerramos este primeiro número da Heterotópica. Nesse artigo, os autores mostram como a linguística cognitiva pode contribuir para uma perspectiva de análise discursiva. Para isso, analisam discursivamente os relatórios chilenos sobre os Direitos Humanos produzidos em diferentes momentos da história e mostram o modo como as propostas da linguística cognitiva contribuem para a compreensão de fenômenos sociais.

A revista Heterotópica inicia assim sua trajetória destacando, de maneira não exaustiva, o percurso epistemológico de constituição, desenvolvimento, transformações e consolidação deste campo de trabalho tão profícuo que se denominou Análise do Discurso. Mostramos, com isso, diferentes possibilidades de adentrar a problemática do discurso e do sentido, e julgamos, finalmente, contribuir tanto para a expansão desse campo de pesquisa quanto para o aprofundamento de questões histórico-sociais e linguísticas importantes de e para o nosso tempo.

\section{Referências}

ALTHUSSER, Louis. Ideologia e Aparelhos Ideológicos de Estado: notas a uma pesquisa. Rio de Janeiro: Graal, 1992.

BACHELARD, Gaston. A epistemologia. Lisboa: Edições 70, 2006.

BLANCHÉ, Robert. A Epistemologia. Tradução Natália Couto. Lisboa: Editorial Presença, 1988.

CANGUILHEM, Georges. Michel Foucault: morte do homem ou esgotamento do Cogito?. Tradução Fábio Ferreira de Almeida. Goiânia: Edições Ricochete, 2012.

CONEIN, Bernard; et al. (Orgs). Materialidades Discursivas. Campinas: Editora da UNICAMP, 2016. 
FOUCAULT, Michel. As palavras e as coisas. São Paulo: Martins Fontes, 2007.

FOUCAULT, Michel. A arqueologia do saber. Rio de Janeiro: Forense Universitária, 2008.

FOUCAULT, Michel. De espaços outros. Estudos Avançados, São Paulo, v. 27, n. 79., 2013. Disponível em: <http://www.scielo.br/scielo.php?script=sci_arttext\&pid=S010340142013000300008\&lng=en\&nrm=iso $>$. Acesso em: 20 maio 2019. DOI: https://doi.org/10.1590/S0103-40142013000300008

MALDIDIER, Denise. Elementos para uma história da Análise do Discurso na França. In: ORLANDI, Eni (Org.). Gestos de Leitura. Campinas: Editora da UNICAMP, 1994.

MALDIDIER, Denise. A Inquietação do Discurso: (Re)ler Pêcheux Hoje. Campinas: Editora da UNICAMP, 2003.

PAVEAU, Marie-Anne; SARFATI, Georges-Elias. As grandes teorias da linguística: da gramática comparada à pragmática. Tradução Maria do Rosário Gregolin, Vanice Oliveira Sargentini, Cleudemar Alves Fernandes. São Carlos: Claraluz, 2006.

PÊCHEUX, Michel. Análise do Discurso: três épocas (1983). In: GADET, Françoise; HAK, Tony. Por uma Análise Automática do Discurso: uma Introdução à Obra de Michel Pêcheux. Campinas: Editora da UNICAMP, 1990a, p. 311-318.

PÊCHEUX, Michel. Análise Automática do Discurso (AAD-69). In: GADET, Françoise; HAK, Tony. Por uma Análise Automática do Discurso: uma Introdução à Obra de Michel Pêcheux. Campinas: Editora da UNICAMP, 1990b, p. 61-105.

PÊCHEUX, Michel. Lecture et mémoire: projet de recherche. In: MALDIDIER, Denise. L'Inquiétude du Discours - textes de Michel Pêcheux. Paris: Éditions des Cendres, 1990c.

PÊCHEUX, Michel. Semântica e Discurso: uma Crítica à Afirmação do Óbvio. Campinas: Editora da UNICAMP, 1997a.

PÊCHEUX, Michel. Só há causa daquilo que falha ou o inverno político francês: início de uma retificação. In: PÊCHEUX, Michel. Semântica e Discurso: uma crítica à afirmação do óbvio. Campinas: Editora da UNICAMP, 1997b, p. 293-307.

PÊCHEUX, Michel. Discurso: estrutura ou acontecimento. Tradução Eni Orlandi. Campinas: Pontes, 1997c.

PÊCHEUX, Michel. Sobre a (des-)construção das teorias linguísticas. Línguas e instrumentos linguísticos. Campinas: Pontes, 1998.

PÊCHEUX, Michel. Sobre os Contextos Epistemológicos da Análise do Discurso. Escritos, Campinas: Nudecri, n. 4, p. 7-16, 1999. Disponível em: <https://www.labeurb.unicamp.br/portal/pages/pdf/escritos/Escritos4.pdf>. Acesso em: 17 abr. 2019. 
PÊCHEUX, Michel. Especificidade de uma disciplina de interpretação (A Análise de Discurso na França). In: PÊCHEUX, Michel. Análise de Discurso. Textos escolhidos por Eni Orlandi. Campinas: Pontes, 2011, p. 227-230.

PÊCHEUX, Michel; FUCHS, Catherine. A propósito da análise automática do discurso: atualização e perspectivas (1975). In: GADET, Françoise; HAK, Tony. Por uma Análise Automática do Discurso: uma Introdução à Obra de Michel Pêcheux. Campinas: Editora da UNICAMP, 1990, p. 163-187.

PÊCHUX, Michel; GADET, Françoise. A Língua inatingível: o discurso na história da linguística. Campinas: Pontes, 2004.

PÊCHEUX, Michel; HAROCHE, Claudine; HENRY, Paul. A Semântica e o corte saussuriano: língua, linguagem, discurso. In: BARONAS, Roberto Leiser (Org.). Análise do Discurso: apontamentos para uma história da noção-conceito de formação discursiva. São Carlos: Pedro e João Editores, 2011, p. 13-32.

SAUSSURE, Ferdinand. Curso de Linguística geral. São Paulo: Cultrix, 2006. 